\title{
DUAL TARGETING OF PIK3/AKT/mTOR and IGF1/KRAS/BRAF PATHWAYS IN AN IN VITRO MODEL OF OVARIAN CANCER: STRATEGIES FOR CELL PROLIFERATION CONTROL
}

de Angelis $C^{1}$, Galdiero $G^{3}$, Pivonello $C^{3}$, Patalano $R^{3}$, Bifulco $G^{4}$, Di Spiezio Sardo $A^{5}$, Alviggi $C^{4}$, De Placido $G^{4}$, Colao $A^{3}$, Pivonello $R^{3}$.

${ }^{1}$ I.O.S. \& COLEMAN Srl - Naples, ${ }^{2}$ CEINGE - Naples, ${ }^{3}$ Dip. Medicina Clinica e Chirurgia - Federico II University of Naples, ${ }^{4}$ Dip. Neuroscienze e Scienze Riproduttive ed Odontostomatologiche - Federico II University of Naples, ${ }^{5}$ Dip. Sanità Pubblica - Federico II University of Naples.

\section{OBJECTIVES}

Ovarian cancer $(\mathrm{OC})$ is the most lethal gynecological cancer. Debulking surgery and platinum-based chemotherapy are the cornerstone of management; however, after a partial initial response, tumors invariably relapse. Therapeutic approaches should account for interindividual heterogeneity since OC histiotypes show distinct genetic profile. A2780 cell line has been annotated as high grade serous OC (HGSOC); nevertheless, recent research underlined that their genetic and molecular background are much closer to the clear cell/endometrioid histiotypes $[1,2]$, characterized by mutations in $\mathrm{PIK} 3 / \mathrm{AKT} / \mathrm{mTOR}$ and IGF1/KRAS/BRAF pathways, partially responsible for chemoresistance. The aim of the current study was to assess the in vitro effects on cell proliferation of the mTORC 1 inhibitor everolimus (EVE), the mTORC1/2 inhibitor OSI027 and the IGF1-R inhibitor OSI906, alone and in combinations, in A2780 cells.

\section{REFERENCES}

\section{1) Anglesio MS et al., Type-Specific Cell} Line Models for Type-Specific Ovarian Cancer Research. 2013

2) Beaufort CM et al., Ovarian Cancer Cell Line Panel (OCCP): Clinical

Importance of In Vitro Morphological Subtypes. 2014

\section{Fig. 4 EVE 1pM + OSI027 100nM 48h}

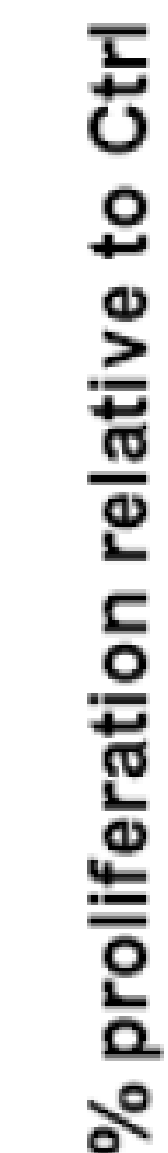

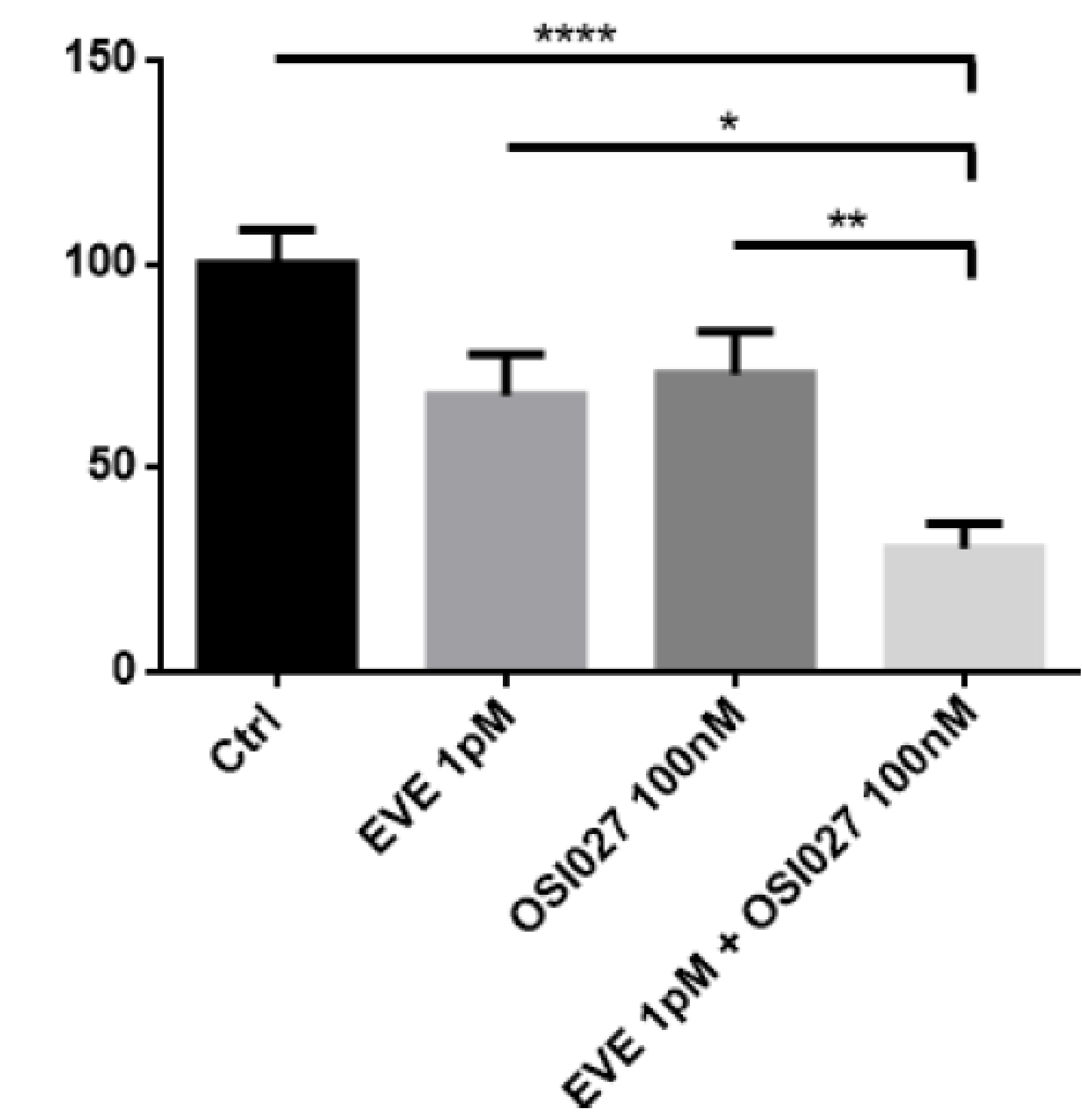

\section{METHODS}

Dose-time response curves were obtained in A2780 treated for 24, 48, and 72 hours and 6 days with compounds given as single agent at concentrations ranging from $1 \mu \mathrm{M}$ to $1 \mathrm{pM}$ and with combinations of drugs administered for 48 and 72 hours at selected concentrations: EVE 100pM, 1pM and 10fM was combined with OSI906 100nM, 10nM and 1nM; OSI027 and OSI906 were combined at $100 \mathrm{nM}, 10 \mathrm{nM}$ and $1 \mathrm{nM}$. At the end of treatments, cells were lysed by sonication in $\mathrm{NH}_{3}$-Triton X100 buffer for 10". DNA was stained in Hoechst Dye and DNA content was assessed by Victor ${ }^{\mathrm{TM}} \mathrm{X} 4$ plate reader at 460 $\mathrm{nm}$. Clonogenic assay was performed on A2780 cells treated for 14 days with compounds given as single agent at concentrations ranging from $1 \mu \mathrm{M}$ to $10 \mathrm{fM}$; colonies size and cell number were evaluated under an inverted bright field microscope and photographed.
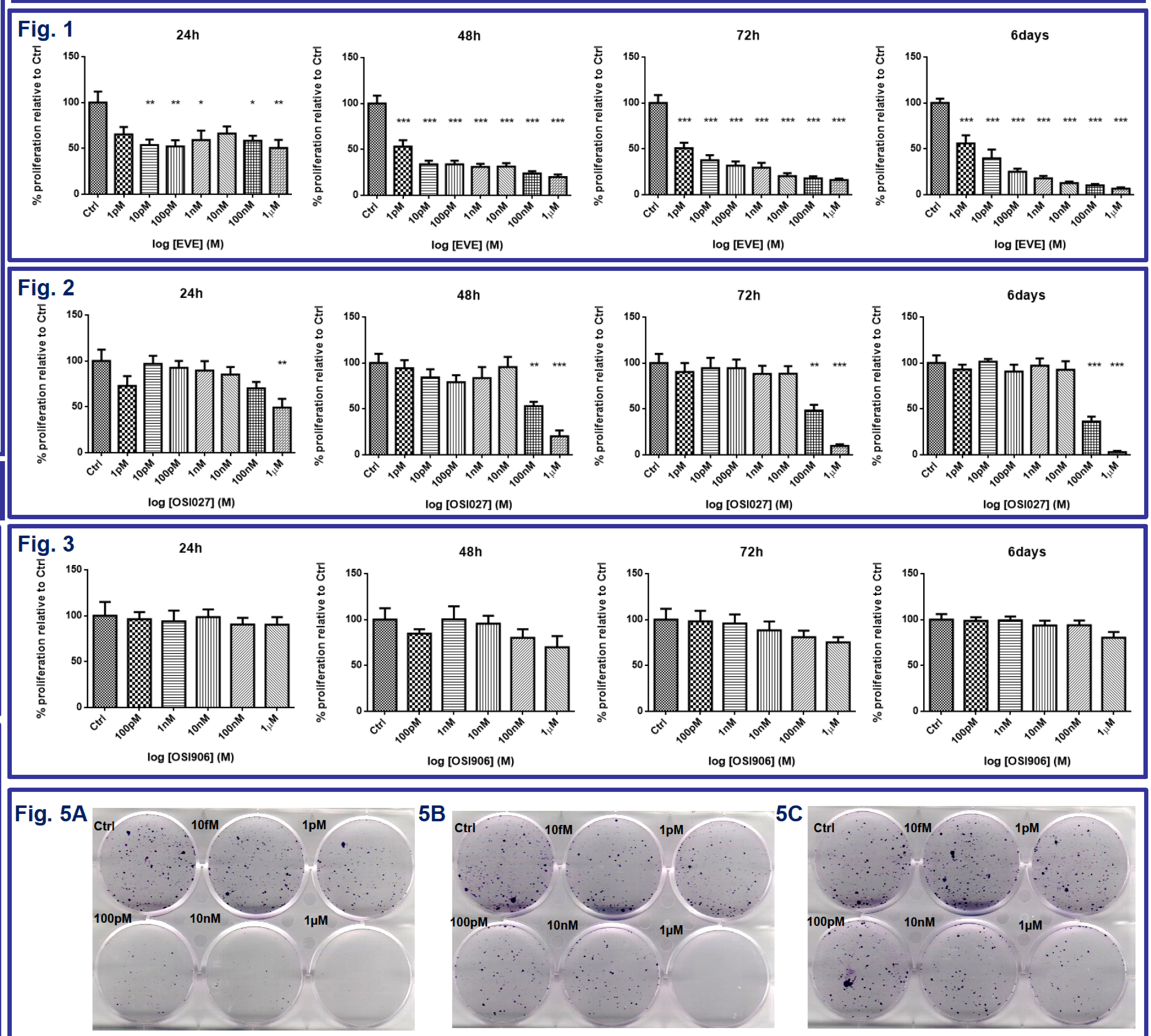

RESULTS

EVE significantly inhibited A2780 cell proliferation in a dose/time dependent manner at all tested concentrations and time-points (max. inhibition $94 \%$ at $1 \mu \mathrm{M}$ after 6days; $\mathrm{p}<0.001$ ) (Fig. 1). OSI027 significantly inhibited A2780 cell proliferation at the highest concentrations of $1 \mu \mathrm{M}$ and $100 \mathrm{nM}$ at all tested time-points (maximum inhibition $97 \%$ at $1 \mu \mathrm{M}$ after 6days; $\mathrm{p}<0.001$ ) (Fig. 2). OSI906 displayed a not-significant and slight dose dependent trend in the inhibition of A2780 cell proliferation (Fig. 3). All the tested combinations of EVE+OSI027 and EVE+OSI906 significantly inhibited A2780 cell proliferation in a dose/time dependent manner, compared to controls; moreover, the co-treatments showed a stronger inhibitory effect on cell proliferation, compared to single compounds, although this result did not reach the statistical significance. However, the combination EVE 1pM+OSI027 100nM showed a significant additive/synergistic effect, compared to single compounds, after 48 hours of treatment (Fig. 4). EVE (Fig. 5A), OSI027 (Fig. 5B) and OSI906 (Fig. 5C) dose dependently inhibited A2780 cells colony formation.

\section{CONCLUSIONS}

